Disclosure of Interests: None declared DOI: 10.1136/annrheumdis-2019-eular.3938

\section{THU0637 ACADEMIC ACHIEVEMENT, EMPLOYMENT STATUS, WORK PRODUCTIVITY AND ACTIVITY IMPAIRMENT IN ADULTS WITH JUVENILE IDIOPATHIC ARTHRITIS (JIA): DETERMINANTS AND CONSEQUENCES}

Chengappa Kavadichanda, Karunya Ravi, Vir Negi. Jawaharlal Institute of Postgraduate Medical Education and Research, Clinical Immunology, Puducherry, India

Background: Changes occurring in childhood due to JIA leads to activity and work impairment during their transition to adulthood. The factors impairing work and overall activity among adults with JIA need to be explored to formulate policy decisions and rehabilitation measures.

Objectives: - To assess the level of academic achievement, employment, work productivity and activity impairment among adults suffering from JIA - To identify factors determining activity impairment among adults with JIA

Methods: Consecutive adults classified as JIA (1) were included. Consenting patients filled a questionnaire comprising of demographic details, occupational/educational status, Indian health associated questionnaire (iHAQ), Work Productivity and Activity Impairment score (WPAI) (2)in the language of their choice. Clinical evaluation for disease activity and damage was done and remission was assessed by Wallace criteria. Remission was defined as ever remission: $>3$ months and sustained remission: $\geq 6$ months of disease control. Appropriate statistical tests to assess association and correlation of various factors with WPAI were used.

Results: Demography $(n=51)$ is depicted in table 1 . Never attaining remission resulted in significantly higher college dropouts ( 8 vs $17, \mathrm{p}<0.05$ ), functional impairment (mean $\mathrm{HHAQ} 1.08$ vs $0.5, \mathrm{p}<0.05$ ) and articular damage (mean JADI A 3 vs $8, p<0.01$ ). Disease duration, JADI $A$ and iHAQ correlated well $\left(r^{2}>.400, p<0.05\right)$ with measures of WPAl (table 2$)$. Assessment of patient variables like gender, occupation, disease activity and remission status (figure 1) showed that women, especially the homemakers and individuals with moderate to high disease activity had significant activity impairment $(\mathrm{P}<0.05)$.

Conclusion: Early effective treatment directly impacts employment levels and activity in adults with JIA. Homemakers in middle- and low-income countries have the most impairment in activity as they cannot alter their work. Replacement costs for homemakers would be an added financial burden to the family and is seldom captured by studies. Our study highlights the need to look further into the indirect and intangible costs involving women that will help policy makers formulate effective economic policies for individuals with JIA.

\section{REFERENCES:}

[1] Petty RE, Southwood TR, Manners P, Baum J, Glass DN, Goldenberg J, et al. International League of Associations for Rheumatology classification of juvenile idiopathic arthritis: second revision, Edmonton, 2001. J Rheumatol. 2004 Feb;31(2):390-2.

[2] Reilly MC, Zbrozek AS, Dukes EM. The validity and reproducibility of a work productivity and activity impairment instrument. Pharmacoeconomics. 1993 Nov;4(5):353-65.

Table 1. Demographic, educational, occupational, health profile and WPAI measures of adults with JIA

\begin{tabular}{lccc}
\hline S.No & Parameter (N=51) & Median & IQR \\
\hline $\mathbf{1}$ & Age & 22 & 8 \\
$\mathbf{2}$ & Disease duration (years) & 9 & 10 \\
$\mathbf{3}$ & Duration of treatment (years) & 5 & 5 \\
$\mathbf{4}$ & WPAI Measures (in percentage) & 40 & 50 \\
& Overall Activity Impairment & 64.06 & 61.66 \\
& Overall Work Impairment (N=14) & 40 & 72.05 \\
& Presentism (N=12) & 33.03 & 51.14 \\
& Absenteeism (N=14) & Frequency (n) & Percentage (\%) \\
& Gender & $\mathbf{2 4 / 2 7}$ & $\mathbf{4 7 . 1 / 5 2 . 9}$ \\
$\mathbf{1}$ & Male/Female & $10 / 41$ & $19.6 / 80.4$ \\
$\mathbf{2}$ & Residential type & & \\
$\mathbf{3}$ & Urban/Rural & 1 & 2 \\
& Educational Status & 10 & 19.6 \\
& Illiterate & 14 & 27.5 \\
& Less than high school & 8 & 15.7 \\
& High School & 18 & 35.3
\end{tabular}

Graduate/Postgraduate or above Housewife
Unemployed/Quit job due to illness JIA Subtype

Systemic Arthritis Oligo Arthritis

Polyarthritis (RF-Negative)

Polyarthritis (RF-Positive)

Enthesitis-Related JIA

Undifferentiated Arthritis Deformity

Absent/Present

Remission

Never/Ever Remission

Sustained remission before/after $18 \mathrm{yrs}$

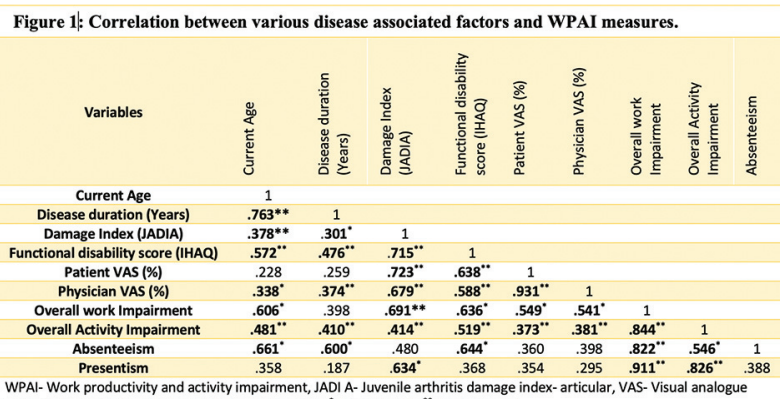

scale, IHAQ- Indian Health associated questionnaire. " P value $<0.05$, " P value $<0.00$
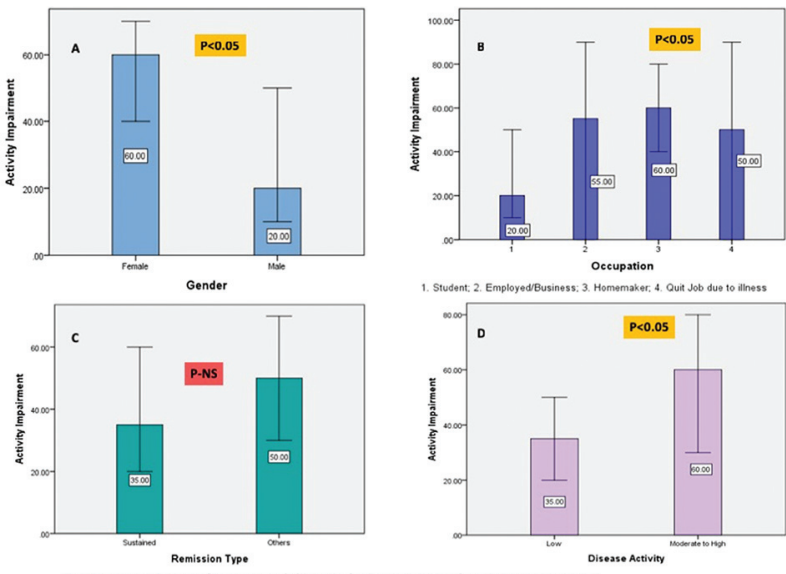

ocoupotion

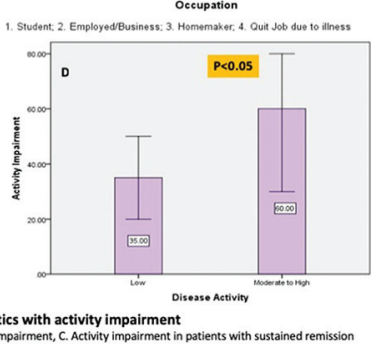

Figure 2: Association of patient and disease characteristics with activity
A. gender and activity impairment, B. Type of coccupation and activity imparirment, C. Activity impairment in patients with sustained remission

Disclosure of Interests: None declared

DOI: 10.1136/annrheumdis-2019-eular.5191

\section{THU0638 CONSIDERATIONS FOR IMPROVING QUALITY OF CARE IN RHEUMATOID ARTHRITIS AND ASSOCIATED COMORBIDITIES}

Tore K. Kvien ${ }^{1}$, Karel Pavelka ${ }^{2}$, Joaquim Polido-Pereira ${ }^{3}$, Anne Grete Semb ${ }^{1}$, Magnus Sköld ${ }^{4}$, Alejandro Balsa ${ }^{5}$, Neil Betteridge ${ }^{6}$, Maya Buch ${ }^{7}$, Patrick Durez ${ }^{8}$, Ennio Favalli ${ }^{9}$, Guillaume Favier ${ }^{10}$, Cem Gabay ${ }^{11}$, Rinie Geenen ${ }^{12}$, Ioanna GouniBerthold ${ }^{13}$, Frank van den Hoogen ${ }^{14}$, Alison Kent ${ }^{15}$, Lars Klareskog ${ }^{4}$,

Mikkel Ǿstergaard ${ }^{16}$, Maxime Dougados ${ }^{17}{ }^{1}{ }^{1}$ Diakonhjemmet Hosp, Oslo, Norway,

${ }^{2}$ Inst Rheumatology, Prague, Czech Republic; ${ }^{3}$ Hosp Santa Maria, Lisbon,

Portugal; ${ }^{4}$ Karolinska U Hosp, Stockholm, Sweden; ${ }^{5}$ Hosp U La Paz, Madrid,

Spain; ${ }^{6}$ Betteridge Assoc, London, United Kingdom; ${ }^{7}$ Chapel Allerton Hosp, Leeds, United Kingdom; ${ }^{8} \mathrm{Clin} \cup$ Saint-Luc, Brussels, Belgium; ${ }^{9}$ Gaetano Pini Inst, Milan,

Italy; ${ }^{10}$ KPMG, London, United Kingdom; ${ }^{11}$ Geneva U Hosp, Geneva, Switzerland;

${ }^{12}$ Utrecht U, Utrecht, Netherlands; ${ }^{13} \mathrm{U}$ Cologne, Cologne, Germany, ${ }^{14}$ Sint

Maartenskliniek, Nijmegen, Netherlands; ${ }^{15}$ Salisbury Hosp, Salisbury, United Kingdom; ${ }^{16}$ Rigshospitalet, Copenhagen, Denmark; ${ }^{17}$ Cochin Hosp, Paris, France

Background: The presence of comorbidities in patients with rheumatoid arthritis (RA) contributes to increased morbidity and mortality ${ }^{(1)}$. Patients 
with RA have an increased risk of comorbidities e.g. interstitial lung (IL) disease $\left(7.7 \%\right.$ incidence ${ }^{(2)}$; up to $60 \%$ IL abnormalities in early $\mathrm{RA}^{(3)}$ ), depression (up to $\left.200 \%{ }^{(4)} ; 16.8 \%{ }^{(5)}\right)$, cardiovascular disease $\left(40-70 \%{ }^{(6)}\right.$; $5-12.9 \%{ }^{(7)}$ ) and diabetes (IR of 8.6 per 1000 person-years ${ }^{(8)} ; 20 \%{ }^{(9)}$ ). Yet, there are few comprehensive recommendations on the management of RA-related comorbidities.

Objectives: This study aimed to identify models of good quality care for patients with RA and their associated comorbidities in Europe and understand how these practices can be widely implemented.

Methods: Existing published recommendations across Europe on good practice in RA care including screening/managing selected comorbidities were reviewed. Team members of 12 specialist centres across Europe were interviewed. The interventions identified were reviewed and prioritised to form a selection of considerations by a consensus process involving 18 experts including rheumatologists, a patient rep., a nurse and also RA comorbidity specialists: cardiologist, psychologist, pulmonologist and diabetologist.

Results: The interventions were prioritised for each patient profile:

a. suspected RA:

1. rapid access to care (online referral, triage, ultrasound-guided diagnosis)

2. enhanced communication with primary care (hotline, education sessions)

3. early arthritis clinic (timely clinical assessment and diagnosis)

b. recently diagnosed:

1. enabling self-management (self-monitoring and disease activity management support)

2. early arthritis clinic

3. comprehensive comorbidity assessment (standalone or in conjunction with RA appointment)

c. established disease:

1. dedicated comorbidity specialist

2. integrating patient registries into daily clinical practice

3. enabling self-management

Eleven other interventions were identified including task-shifting to nonphysician healthcare professionals, tailored education to patients and family members, and developing care networks.

Conclusion: Despite limited European recommendations on management of RA comorbidities, a range of good practice care model interventions across Europe were identified which are non-complex, high-impact and meaningful. Next step will be to assess how these care models can be implemented in different healthcare systems for the benefit of patients with RA.

\section{REFERENCES:}

[1] Dougados, et al. Ann Rheum Dis 2014; 73:62

[2] Bongartz, et al. Arthritis Rheum 2010; 62(6):1583

[3] Reynisdottir, et al. Arthritis Rheum 2014; 66:31

[4] Sheehy, et al. Rheum 2006; 45(11):1325-1327

[5] Matcham, et al. Rheumatology 2013; 52:2136

[6] Holmquist, et al. Ann Rheum Dis 2017; 76:1642

[7] Van Halm, et al. Ann Rheum Dis 2009; 68(9):1395

[8] Solomon D, et al. Ann Rheum Dis 2010; 69(12):2114

[9] Albrecht K, et al. Rheum 2018; 57(2):329-336

Disclosures: Most authors have received funding from the industry including Sanofi Genzyme who solely funded this study

Disclosure of Interests: Tore K. Kvien Grant/research support from: AbbVie, BMS, MSD, Pfizer, Roche and UCB., Consultant for: AbbVie, Biogen, BMS, Boehringer Ingelheim, Celgene, Celltrion, Eli Lilly, Hospira, MerckSerono, MSD, Novartis, Oktal, Orion Pharma, Pfizer, Roche, Sandoz, Sanofi, Mylan and UCB, Speakers bureau: AbbVie, Biogen, BMS, Boehringer Ingelheim, Celgene, Celltrion, Eli Lilly, Hospira, Merck-Serono, MSD, Novartis, Oktal, Orion Pharma, Pfizer, Roche, Sandoz, Sanofi and UCB, Karel Pavelka: None declared, Joaquim Polido-Pereira: None declared, Anne Grete Semb: None declared, Magnus Sköld: None declared, Alejandro Balsa Grant/research support from: Abbvie, Pfizer, Novartis, BMS, Nordic, Sanofi, Consultant for: Abbvie, Pfizer, Novartis, BMS, Nordic, Sanofi, Sandoz, Lilly, Paid instructor for: Pfizer, Speakers bureau: Pfizer, Novartis, UCB, Nordic, Sanofi, Sandoz, Lilly, Neil Betteridge Consultant for: Amgen, Eli Lilly, Grunenthal, GSK, Heart Valve Voice, Janssen, Roche, Sanofi Genzyme and Sanofi Regeneron, Speakers bureau: Amgen, Eli Lilly, Grunenthal, GSK, Heart Valve Voice, Janssen, Roche, Sanofi Genzyme and Sanofi Regeneron, Maya Buch Grant/ research support from: Pfizer LTD, UCB, Consultant for: AbbVie, Eli Lilly, EMD Serono, Pfizer Ltd., Sanofi, Patrick Durez Speakers bureau: Bristol-
Myers Squibb, Eli Lilly, Sanofi, Celltrion, Ennio Favalli: None declared, Guillaume Favier: None declared, Cem Gabay Grant/research support from: Roche, Pfizer, AB2 Bio Ltd, Consultant for: Roche, Pfizer, Lilly, AbbVie, Sanofi, Regeneron, Bristol-Myers Squibb, Novartis, UCB, AB2 Bio Ltd, Debiopharm, Rinie Geenen: None declared, loanna Gouni-Berthold: None declared, Frank van den Hoogen: None declared, Alison Kent None declared, Lars Klareskog Grant/research support from: Yes, but no for the presented study., Mikkel Ǿstergaard Grant/research support from: Abbvie, Celgene, Centocor, Merck, Novartis, Consultant for: Abbvie, BMS Boehringer-Ingelheim, Celgene, Eli Lilly, Hospira, Janssen, Merck, Novartis, Novo, Orion, Pfizer, Regeneron, Roche, and UCB, Speakers bureau: Abbvie, BMS, Boehringer-Ingelheim, Celgene, Eli Lilly, Hospira, Janssen, Merck, Novartis, Novo, Orion, Pfizer, Regeneron, Roche, and UCB, max ime dougados Grant/research support from: Eli Lilly and Company, Pfizer AbbVie, and UCB Pharma, Consultant for: Eli Lilly and Company, Pfizer, AbbVie, and UCB Pharma

DOI: 10.1136/annrheumdis-2019-eular.4285

\section{THU0639 AUTOMATED CAPTURE AND HIGH UPTAKE RATES OF PATIENT REPORTED OUTCOME MEASURES IN ROUTINE RHEUMATOLOGY PRACTICE}

Manjari Lahiri ${ }^{1,2}$, James Yip ${ }^{1,3} .{ }^{1}$ Yong Loo Lin School of Medicine, National University of Singapore, Department of Medicine, Singapore, Singapore; ${ }^{2}$ National University Hospital, Division of Rheumatology, University Medicine Cluster, Singapore, Singapore; ${ }^{3}$ National University Hospital, Department of Cardiology, Singapore, Singapore

Background: Patient reported Outcome Measures (PROMs) are an integral part of value based healthcare and outcomes that matter to patients however resource and time constraints are often barriers for routine collection in clinic.

Objectives: We piloted an automated, electronic collection of PROMs for patients attending an outpatient specialist rheumatology clinic.

Methods: All patients with a clinic appointment were sent an automated text message, one day before their scheduled doctor's appointment, with a hyperlink to fill in the Routine Assessment of Patient Index Data (RAPID3) [0-30, 30 being worst, calculated as the sum of physical function measured using the 10-item multidimensional health assessment questionnaire (mdHAQ), pain visual analogue scale (VAS), and patient global VAS questionnaire]. The text message was personalised with the attending physician's name and thumbnail photograph and the questionnaire was presented in the patient's preferred language (English or simplified Chinese) by detecting their phone configuration. RAPID3 responses flowed back to the electronic medical record and were available for the attending clinician to view during the clinic consult the next day. Patients who did not fill in the questionnaire within 6 hours were sent a reminder, and those still remaining were encouraged to fill it in the clinic waiting room. Hardcopy flyers were distributed to inform patients of the initiative and clinicians were encouraged to discuss the responses at the clinic visit. Patients were sent the survey only once during the study period. Weekly usdage reports were sent to the clinicians (Figure 1).

Results: 4078 patients [mean (SD) age 55.8 (16.3) years, 67.9\% female, $70.6 \%$ Chinese] were sent the text message invitation over 6 months, of which $64.4 \%$ responded. Diagnosis data from SNOMED codes were available for 2262 patients. The most common primary diagnoses were rheumatoid arthritis $(653,29,5 \%)$, Spondyloarthritides $(\mathrm{SpA})$, including psoriatic arthritis $(318,14.4 \%)$ and lupus $(310,14 \%)$. Data on disease duration clinical features and medications were not available for this study. The mean (SD) mdHAQ score (range $0-3,3$ being the worst) was $0.3(0.5)$ mean (SD) pain-VAS (0-10, 10 being worst) was 2.4 (2.3), patient global was 2.6 (2.2) and RAPID3 was 6.1 (5.2). On multivariable logistic regression, age $(\mathrm{OR}=0.38,95 \% \mathrm{Cl} 0.32,0.44$ for the top tertile), gender (OR $1.22,95 \% \mathrm{Cl} 1.06,1.4$ for females), race $(\mathrm{OR}=0.79,95 \% \mathrm{Cl} 0.64$ 0.98 for Indian vs. Chinese race) and treating physician (OR 0.7, 95\% $\mathrm{Cl} 0.61,0.8$ for junior vs. senior doctor) were independent predictors of survey response, while primary rheumatic disease was not (Figure 2). Ten of 11 clinicians (from 13 surveyed) found the information from PROMs useful, and $8 / 11$ supported expansion of the pilot project to include more PROMs. Lack of time was cited as the biggest challenge to implementing PROMs routinely.

Conclusion: Automated collection of PROMs in routine clinical care is feasible with high uptake rates and minimal clinician burden.

[1] Figure 1: Weekly usage reports 

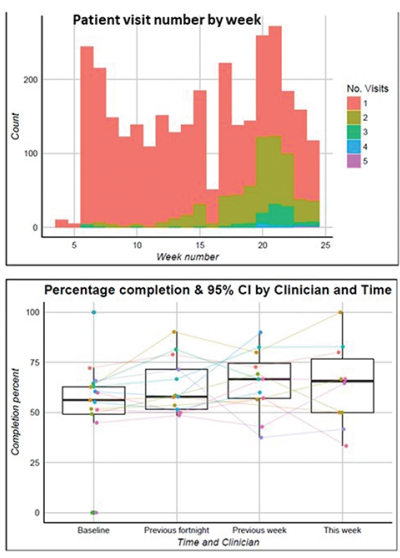

Figure 2. Predictors of Survey Response
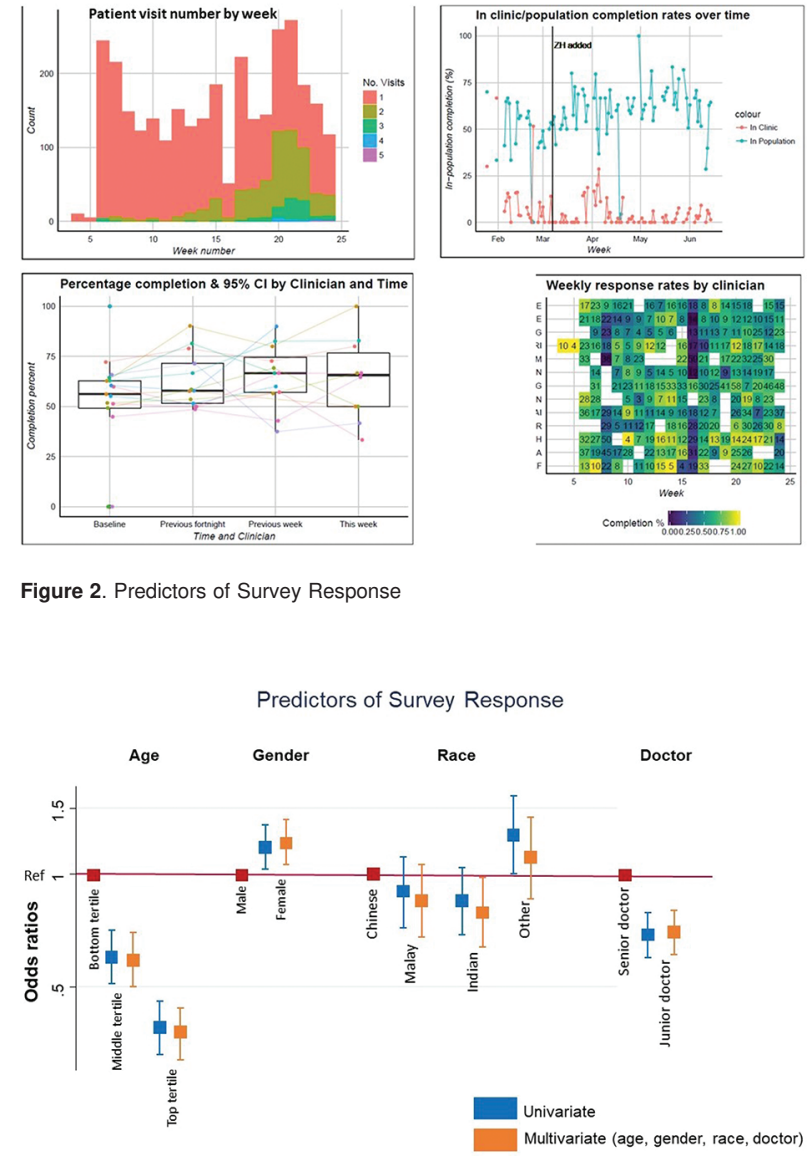

Acknowledgement: Ramasamy Thirumugam from the Academic Informatics Office, National University Hospital, for setting up the system

Disclosure of Interests: Manjari Lahiri Grant/research support from: Grant support from Pfizer. I am the site PI for the Singapore National Biologics Register which is funded by multiple pharmaceutical companies; however I do not directly receive any funds for this., Consultant for: Advisory board for Elli Lilly, James Yip: None declared

DOI: 10.1136/annrheumdis-2019-eular.3872

\section{THU0640 EARLY RETIREMENT ATTRIBUTED TO RHEUMATOID ARTHRITIS AND ITS PREDICTORS IN PORTUGAL}

Mariana Luis ${ }^{1}$, Ana Rita Cunha ${ }^{2}$, Helena Assunção ${ }^{1}$, Ana Rita Prata ${ }^{1}$ Luisa Brites ${ }^{1}$, Flavio Costa ${ }^{1}$, João Dinis de Freitas ${ }^{1}$, Stephanie Silva', Anabela Barcelos ${ }^{2}$, Catia Duarte ${ }^{1}$, José Antonio P. Da Silva ${ }^{1} .{ }^{1}$ Centro Hospitalar e Universitário de Coimbra, Coimbra, Portugal; ${ }^{2}$ Centro Hospitalar do Baixo Vouga, Aveiro, Portugal

Background: Work disability is a common consequence of Rheumatoid Arthritis (RA) with economic implications for both the patient and society. Scarce information is available on work and disease-related factors associated with early retirement in Portugal.

Objectives: To evaluate the rate of early retirement due to RA. Secondary aim consists in the identification of its main predictors, both work and disease-related.

Methods: Retrospective cohort study involving two national rheumatology centers, including patients with RA according the ACR/EULAR 2010 or the 1987 ACR Classification Criteria for RA. Patients retired prior to RA diagnosis, never-employed or with missing information on current work status were excluded. Type of work was independently classified as non-manual/ manual/heavy manual by two authors based on patient's occupation with excellent inter-agreement (Cohen's kappa coefficient 0.91). Retirement due to RA versus retirement for other reasons were compared using T-test and Chi-2 test as adequate. Variables with $p<0.05$ in univariate analysis and other potential predictors selected on clinical and epidemiological grounds were included in multivariable binary logistic regresssion.

Results: 492 patients were included $(80.3 \%$ female, aged $60.9 \pm 13.1$ years-old, mean disease duration $15.9 \pm 10.5$ years). Until the present time, $45.1 \%(n=222)$ of the patients retired, this being due to RA in
$59.5 \%$ of the cases. Early retirement due to RA translated into 6.5 years of active work lost, compared to retirement due to other causes. Patients who retired due to RA are more likely to be younger at diagnosis $(49.6$ \pm 9.0 vs. $56.1 \pm 8.6$ years-old; $p<0.01)$, female $(82.6 \%$ vs. $68.9 \%$, $\mathrm{p}<0.01)$, have longer disease duration $(23.2 \pm 10.7$ vs. $18.3 \pm 9.9$ years, $p<0.01)$ and lower educational level $(4.5 \pm 2.3$ vs. $6.0 \pm 4.1$ school years, $p<0.01)$. In the multivariate analysis, disease-related predictors for early retirement were: disease duration (OR: 1.11; $95 \%$ Cl 1.08-1.13/ year), erosive disease (OR: $4.4595 \% \mathrm{Cl} 2.37-8.35$ ) and the need for biologic therapy switching (OR:1.37; $95 \% \mathrm{Cl} 1.02-1.83$ ). Work-related predictors were: educational level (OR: $0.75 ; 95 \% \mathrm{Cl} 0.68-0.81 /$ year) and heavy manual type of work (OR: $1.62 ; 95 \% \mathrm{Cl} 1.16-2.26$ ).

Conclusion: Early retirement is still common among patients with RA: $60 \%$ in this cohort. The main reasons for early retirement are associated with the disease itself, but work-related factors also play a relevant role.

\section{REFERENCES:}

[1] P. A. Laires, M. Gouveia. Association of rheumatic diseases with early exit from paid employment in Portugal. Rheumatol Int (2014) 34:491-502.

[2] K. Puolakka, H. Kautiainen, T. Mottonen, P. Hannonen, et al. Predictors of productivity loss in early rheumatoid arthritis: a 5 year follow up study. Ann Rheum Dis 2005;64:130-133.

[3] D. Lacaille, S. Sheps, J. J. Spinelli, A. Chalmers, J. M. Escaile. Identification of modifiable work-related factors that influence the risk of work disability in rheumatoid arthritis. Arthritis Rheum. 2004 Oct 15;51(5):843-52.

Disclosure of Interests: None declared

DOI: 10.1136/annrheumdis-2019-eular.1635

\section{THU0641 USE OF A WEB-BASED RHEUMATOLOGY PATIENT MANAGEMENT PORTAL}

Tin Aung ${ }^{1}$, Robert Sharpe ${ }^{2}$, Roope Manhas ${ }^{1}$, Stuart Kyle ${ }^{1} .{ }^{1}$ Northern Devon Healthcare NHS trust, Rheumatology, Barnstaple, United Kingdom; ${ }^{2}$ Medimetric, Barnstaple, United Kingdom

Background: The benefit of incorporating tele-rheumatology into standard care is increasingly recognised. In January 2017, we introduced a webbased Rheumatology Patient Management Portal (RPMP), developed by MedMet, to our rheumatology patients at the North Devon District Hospital. In 2018 the portal service was fully operational. Suitable patients included undifferentiated inflammatory arthritis, rheumatoid arthritis, psoriatic arthritis and spondyloarthritides. Patients were consented to collected data such as diagnosis, treatment and disease activity onto the RPMP. For a selected group of patients who agreed to their email use, we set up schedules in the form of email reminders for them to complete PROMs (patient reported outcome measures) such as Health Assessment Questionnaire, Spinal Pain, Bath Ankylosing Spondylitis Disease Activity Index and Work Productivity and Activity Impairment. Patients can also report disease flares electronically, which is acknowledged by a health care professional who will contact them with advice as necessary.

Objectives: To understand patient participation in the use of the RPMP, between 01.01 .18 and 31.12.18.

To develop a cohort of clinically stable patients who can self-manage via RPMP use and scheduled PROMs. The potential to remotely manage these patients has the advantage of reducing the number of face-to-face clinic appointments and eventually will lead to setting up a virtual clinic. To examine patient perception on the RPMP use.

To examine whether tele-rheumatology is a useful adjunct to standard care. Methods: The data was collected from interrogating the web-based RPMP database. Specific data was reviewed including; total number of patients on the portal, number of patients consenting to use their email, number of PROMs completed on the RPMP, number of flares reported and time to acknowledgment. In order to gain further understanding of user experience, a survey questionnaire (figure 1) was sent on 14.01.19.

Results: In total we have 883 patients recruited to the RPMP.

During the study period of one year, 289 patients have consented to share their emails and set up schedules. Therefore $33 \%$ of patients on the RPMP are using their emails through 2018. 310 patients responded to their portal request to complete a schedule. 758 PROMs were completed as part of the schedule response. 1744 PROMs were completed face to face whilst in standard clinic review. Therefore, 30\% of PROMs were completed through a scheduled response. 55 patients contacted us through the RPMP to report a flare. The average time to acknowledging a flare is 37 hours. $78 \%$ of flare reports were acknowledged within 3 days. Results from the survey of patient experience as follow: number of patients responded to the survey was 99 and respond rate was $34 \%$. 
Among them, 94\% reported the RPMP as easy to use, 54\% found that RPMP helped them in understanding their rheumatology condition and $25 \%$ reported a flare through the RPMP.

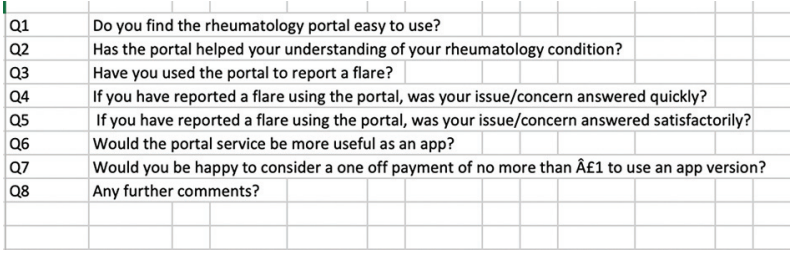

Conclusion: A large number of our rheumatology patients have consented to use the RPMP and their email. Uptake of the RPMP use is increasing (figure 2).

We have identified a significant proportion of 289 patients using the portal and email that could be targeted for virtual clinic use. Our data showed that use of tele-rheumatology in conjunction with standard care has potential to reduce number of standard clinic appointments however further work is required to investigate this.

Feedback from clinical staff is that having PROMs completed prior to consultation gives more time to discuss key issues whilst facilitating appropriate monitoring. The survey showed that majority of patients found the RPMP easy to use and helpful in understanding their rheumatology condition. The RPMP is an effective monitoring system for selected patients and has improved patient understanding in monitoring their disease activity.

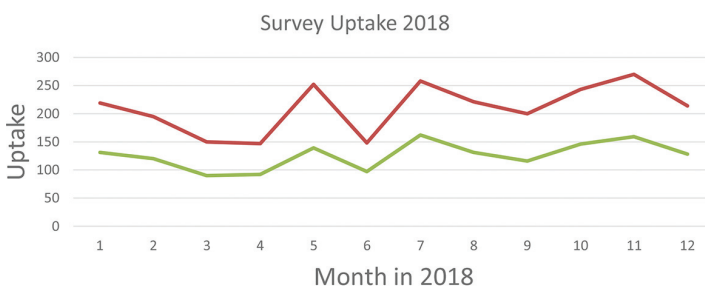

Disclosure of Interests: Tin Aung: None declared, Robert Sharpe: None declared, Roope Manhas: None declared, stuart kyle Consultant for: but no conflict of interest.

DOI: 10.1136/annrheumdis-2019-eular.3311

\section{THU0642 EULAR POINTS TO CONSIDER FOR THE DEVELOPMENT, EVALUATION AND IMPLEMENTATION OF MOBILE HEALTH APPLICATIONS FOR SELF- MANAGEMENT IN PATIENTS WITH RHEUMATIC AND MUSCULOSKELETAL DISEASES}

Aurelie Najm $^{1,2}$, Elena Nikiphorou ${ }^{3}$, Marie Kostine ${ }^{4}$, Christophe Richez ${ }^{4}$, John Pauling ${ }^{5}$, Axel Finckh ${ }^{6}$, Valentin Ritschl ${ }^{7}$, Yeliz Prior ${ }^{8}$, Petra Balazova ${ }^{9}$ Simon Stones ${ }^{10}$, Zoltán Szekanecz ${ }^{11}$, Annamaria lagnocco ${ }^{12}$, Sofia Ramiro ${ }^{13}$, Francisca Sivera ${ }^{14}$, Maxime Dougados ${ }^{15}$, Loreto Carmona ${ }^{16}$, Gerd Rüdiger Burmester ${ }^{17}$, Laure Gossec ${ }^{18}$, Francis Berenbaum ${ }^{19}$. $^{1}$ Nantes University Hospital, Rheumatology, Nantes, France; ${ }^{2}$ INSERM UMR 1238 University of Medicine Nantes, Nantes, France; ${ }^{3}$ King's College London, Rheumatology, London, United Kingdom; ${ }^{4}$ Bordeaux University Hospital, Rheumatology, Bordeaux, France, ${ }^{5}$ Royal National Hospital for Rheumatic Diseases, Bath; and Department of Pharmacy and Pharmacology, University of Bath, United Kingdom, Bath, United Kingdom; ${ }^{6}$ Service de Rhumatologie Hôpital Beau-Séjour, Hôpitaux Universitaires de Genève, Geneve, Switzerland; ${ }^{7}$ Medical University of Vienna, Section for Outcomes Research, Vienna, Austria; ${ }^{8}$ Centre for Health Sciences Research, University of Salford, Salford and Mid Cheshire NHS Foundation Trust Hospitals, Crewe, United Kingdom; ${ }^{9}$ EULAR Young PARE, Zurich, Switzerland; ${ }^{10}$ University of Leeds, Leeds, United Kingdom; ${ }^{11}$ University of Debrecen, Debrecen, Hungary, ${ }^{12}$ Academic Rheumatology Centre, Università degli Studi di Torino, Italy, Torino, Italy; ${ }^{13}$ Leiden University Medical Centre, Leiden, Netherlands; ${ }^{14}$ Hospital General Universitario de Elda, Elda, Spain; ${ }^{15}$ Hopital Cochin, Paris, France; ${ }^{16}$ Instituto de Salud Musculoesquelética, Madrid, Spain; ${ }^{17}$ Charité University Clinic, Berlin, Germany; ${ }^{18}$ Sorbonne Université, Pitié Salpétriere Hospital, Paris, France, ${ }^{19}$ Sorbonne Université, Saint Antoine Hospital, Paris, France

Background: In the expanding era of e-health, a wide range of mobile health applications (apps) have become available to enable people with rheumatic and musculoskeletal diseases (RMDs) to better self-manage their health. However, guidance on the development and evaluation of such apps is lacking.

Objectives: The objective of this EULAR task force was to establish points to consider (PtC) for the development, evaluation and implementation of apps for self-management of RMDs.

Methods: A systematic literature review of app content and development strategies was conducted, followed by a qualitative study with six patients and an online survey of people living with RMDs $(n=394)$. Based on these data and expert opinion, the PtC were formulated in a face-to-face meeting in November 2018 by a multidisciplinary TF panel of experts, including patients, from 10 countries. The level of agreement among the panel in regard to each $\mathrm{PtC}$ was established by anonymous online voting.

Results: Three overarching principles and 10 PtC were formulated (Table). Out of the $10 \mathrm{PtC}$, three were related to patient safety $(1,5,6)$, considered as a critical issue by the panel, along with accuracy of information provided by apps. Three were related to relevance of the content and functionalities $(2,7,9)$ and the importance of apps being tailored to the individual needs of people with RMDs. The requirement for transparency around app developers and funding sources $(3,4)$, along with involvement of relevant health professionals were also raised. Ease of app access across ages and abilities was highlighted (8), in addition to considering the cost-benefit of apps from the outset (10). The level of agreement was high (Table).

Conclusion: These PtC provide guidance on important aspects that should be considered for the development of new apps, the quality assessment of existing apps, as well as for further development of existing apps. As part of the dissemination phase, these PtC will be shared with a larger group of health professionals, patients and app developers and for wider consensus.

\begin{tabular}{|ll|c|}
\hline \multicolumn{1}{|c|}{ Points to consider } & $\begin{array}{c}\text { Level of agreement } \\
\text { mean (SD) }\end{array}$ \\
\hline 1. & $\begin{array}{l}\text { The information content in self-management Apps should be up to date, } \\
\text { scientifically justifiable, user-acceptable and evidence-based where } \\
\text { applicable. }\end{array}$ & $9.8(0.4)$ \\
\hline 2. & $\begin{array}{l}\text { Apps should be relevant and tailored to the individual needs of people with } \\
\text { RMDs. }\end{array}$ & $9.7(0.5)$ \\
\hline 3. & $\begin{array}{l}\text { The design, development and validation of a self-management App should } \\
\text { involve people with RMDs and relevant health care providers. }\end{array}$ & $9.8(0.6)$ \\
\hline $4 . \quad \begin{array}{l}\text { There should be transparency on an Apps' developer, funding source, content } \\
\text { validation process, version updates and data ownership. }\end{array}$ & $9.9(0.3)$ \\
\hline 5. & $\begin{array}{l}\text { Data collection as part of an App must adhere to all applicable regulatory } \\
\text { frameworks, particularly data protection. }\end{array}$ & $9.9(0.3)$ \\
\hline 6. & Apps must not result in physical or emotional harm to people with RMDs. \\
\hline 7. & $\begin{array}{l}\text { Apps could facilitate patient-health care provider communication and } \\
\text { contribute to electronic health records or research. }\end{array}$ & $9.3(1)$ \\
\hline 8. & $\begin{array}{l}\text { App design should consider accessibility of people with RMDs across ages } \\
\text { and abilities. }\end{array}$ & $9.4(0.9)$ \\
\hline 9. & $\begin{array}{l}\text { If a social network is an important component of an App, structures should } \\
\text { be in place to ensure appropriate content moderation. }\end{array}$ & $9.4(0.9)$ \\
\hline 10. & $\begin{array}{l}\text { The rheumatology community should consider the cost-benefit balance of } \\
\text { Apps before its endorsement and/or its promotion. }\end{array}$ & $9.5(0.6)$ \\
\hline
\end{tabular}

Table 1. The 10 Points to Consider.

Acknowledgement: EULAR for funding this project

Disclosure of Interests: Aurelie Najm: None declared, Elena Nikiphorou: None declared, Marie Kostine: None declared, Christophe Richez: None declared, John Pauling: None declared, Axel Finckh Grant/research support from: Bristol-Myers Squibb, Pfizer Inc, Consultant for: AbbVie, A2Bio Bristol-Myers Squibb, MSD, Roche, Pfizer Inc, and UCB, Valentin Ritschl: None declared, Yeliz Prior: None declared, Petra Balazova: None declared, Simon Stones Consultant for: SS has provided consultancy services to Envision Pharma Group, though this is not related to the contents of this abstract., Speakers bureau: SS has undertaken speaking engagements for Actelion, eyeforpharma, Four Health, Janssen and Roche, though these are not related to the contents of this abstract., Zoltán Szekanecz Grant/research support from: Pfizer, UCB, Consultant for: Pfizer, Abbvie, Roche, Sanofi, Lilly, Novartis, Speakers bureau: Pfizer Abbvie, Roche, Sanofi, Lilly, Novartis, Annamaria lagnocco: None declared, Sofia Ramiro Grant/research support from: MSD, Consultant for: AbbVie, Lilly, MSD, Novartis, Pfizer, Sanofi, Speakers bureau: AbbVie, Lilly, MSD, Novartis, Pfizer, Sanofi, Francisca Sivera: None declared maxime dougados Grant/research support from: Eli Lilly and Company, Pfizer, AbbVie, and UCB Pharma, Consultant for: Eli Lilly and Company, Pfizer, AbbVie, and UCB Pharma, Loreto Carmona Grant/research support from: Abbvie, Actelion, Astellas, BMS, Eisay, Gebro Pharma, Grünenthal, Leo Pharma, Lilly, MSD, Novartis, Pfizer, Roche, Sanofi-Aventis and UCB Pharma, Paid instructor for: Novartis, Gerd Rüdiger Burmester Consultant for: Roche, Sanofi-Genzyme, Speakers bureau: Roche, Sanofi-Genzyme, 